\title{
PORÓWNANIE WYNIKÓW ZASTOSOWANIA ALGORYTMÓW GENERALIZACJI KARTOGRAFICZNEJ DO UPROSZCZENIA LINII BRZEGOWEJ WYBRANYCH WÓD POWIERZCHNIOWYCH Z BAZY BDOT10K
}

\author{
PAWEŁ CYBULSKI \\ Uniwersytet im. Adama Mickiewicza w Poznaniu, \\ Wydział Nauk Geograficznych i Geologicznych, Zakład Kartografii i Geomatyki, \\ ul. B. Krygowskiego 10, 61-680 Poznań
}

\begin{abstract}
The article discusses the issue of cartographic generalization of surface waters based on algorithms. In the process of developing topographic maps, spatial databases play an important role, in particular, BDOT10k. According to the regulation which regulates how to make topographic maps, there are no defined principles for generalization. Therefore, the article analyzes the simplification results of three algorithms and compares them with respect to their suitability for cartographic generalization of the chosen surface waters.
\end{abstract}

Keywords: cartographic generalization, geomatics, infrastructure for spatial data, cartography, spatial database

\section{WPROWADZENIE}

Wykorzystanie przestrzennych baz danych do produkcji map topograficznych jest praktyką w ramach infrastruktury informacji przestrzennej w Polsce i w Europie. Prawne standardy w postaci ustaw i rozporządzeń określają, które bazy i rejestry przestrzenne mogą być użyte do opracowania standardowych opracowań kartograficznych w skalach od $1: 10000$ do $1: 1000$ 000. Oprócz tego regulacje mówią o tym, które obiekty i w jaki sposób mogą być reprezentowane w konkretnych skalach. Główną bazą, na podstawie której opracowuje się obecnie mapy topograficzne, jest Baza Danych Obiektów Topograficznych 10k (BDOT10k). Pozwala ona na opracowanie map topograficznych w skalach $1: 10000,1: 25$ 000, $1: 50000$ oraz $1: 100$ 000. Jej prowadzenie, organizację, zakres informacji, tworzenie, aktualizację czy udostępnianie reguluje Rozporządzenie Ministra Spraw Wewnętrznych i Administracji z dnia 17 listopada 2011 r. w sprawie bazy danych obiektów topograficznych oraz bazy danych obiektów ogólnogeograficznych, a także standardowych opracowań kartograficznych (Olszewski 2013).

Dzięki jednej bazie BDOT10k jest możliwe generowanie map topograficznych w czterech różnych skalach, co jest cechą wielorozdzielczych baz danych (multiple representation database). Niesie to z sobą pewne konsekwencje, gdyż 
ten sam element przedstawiony w różnych skalach podlega generalizacji kartograficznej w różnym stopniu, a co się z tym wiąże, jego geometria, a niekiedy i położenie ulegają zmianie. Zatem, aby opracowywać standardowe zobrazowania kartograficzne, takie jak mapy topograficzne, potrzebne są również zasady mówiące o tym, w jaki sposób generalizować wybrane obiekty. Jednak w przypadku BDOT10k zasady generalizacji nie są do końca jasne - są zapisy dotyczące sposobu wprowadzania obiektów do bazy, ale brakuje informacji o tym, jak przeprowadzić generalizację.

Najważniejszy zapis dotyczący generalizacji kartograficznej znajduje się w opisie zasad symbolizacji. Mówi o tym, że woda powierzchniowa jest obszarem zdefiniowanym przez linię brzegową odgraniczającą lustro wody od terenu lądowego przy normalnym poziomie wody. Symbolizacja obiektów jest również formą generalizacji, ponieważ w BDOT10k przyjmuje się np., że wszystkie cieki, które mają szerokość poniżej $5 \mathrm{~m}$, są przedstawiane wyłącznie za pomocą osi geometrycznej cieku, a w przypadku szerokości poniżej $1,5 \mathrm{~m}$ przyjmuje się jednakową grubość linii niezależnie od rzeczywistej szerokości koryta. Kryterium wydzielenia minimalnej powierzchni dla zbiorników wodnych ze wszystkich obiektów wynosi $80 \mathrm{~m}^{2}$ przy minimalnej szerokości $5 \mathrm{~m}$. Poniżej tych wartości zbiorniki nie są prezentowane na mapie topograficznej. Taki rodzaj generalizacji nazywa się wyborem lub selekcją (Medyńska-Gulij 2015, s. 106). Ponadto minimalna odległość pomiędzy dwoma werteksami powinna wynosić $2 \mathrm{~m}$, chyba że dane pozyskano z rejestru o większej szczegółowości. Są to wytyczne dość ogólne, które pozostawiają dużą dozę subiektywizmu generalizacji.

\section{Szczegółowe zasady reprezentacji obiektów w klasie obiektów woda powierzchniowa na mapie}

Są jeszcze szczegółowe informacje odnośnie reprezentacji wody powierzchniowej w każdej ze skal. W skali $1: 10000$ przedstawia się wszystkie obiekty z kategorii wody powierzchniowe, a także wyspy na tych wodach. W skali 1 : 25000 jest wymagane pole powierzchni większe bądź równe $625 \mathrm{~m}^{2}$. Umowny znak składający się z linii brzegowej oraz wody powierzchniowej stosuje się do przedstawienia także wód płynących o szerokości powyżej $0,4 \mathrm{~mm}$ na mapie. Nie łączy się z sobą blisko położonych zbiorników wodnych, poza małym stawami oddzielonymi groblami. Przedstawia się także wszystkie wyspy na jeziorach i stawach. W skali 1 : 50000 woda powierzchniowa musi mieć pole powierzchni większe bądź równe $2500 \mathrm{~m}^{2}$. Użyty jest również znak do przedstawienia wód płynących o szerokości powyżej $0,4 \mathrm{~mm}$ na mapie. Podobnie jak w skali większej nie łączy się zbiorników położonych blisko siebie, oprócz małych stawów oddzielonych groblami. Przedstawia się także wszystkie wyspy. 
W przypadku skali $1: 100000$ stosuje się pole powierzchni większe bądź równe $10000 \mathrm{~m}^{2}$ oraz wody płynące szersze niż $0,4 \mathrm{~mm}$ na mapie. Małe stawy oddzielone groblami łączy się z blisko położonymi zbiornikami. Zbiorniki węższe niż $0,4 \mathrm{~mm}$ na mapie poszerza się, aby światło (odległość) między znakami liniowymi oznaczającymi brzegi zbiornika wynosiło minimum $0,3 \mathrm{~mm}$ na mapie.

Celem tego artykułu jest porównanie poszczególnych algorytmów generalizacji dostępnych w programie ESRI ArcMap do uproszczenia geometrii wybranych jezior znajdujących się w BDOT10k w taki sposób, aby zachowały one ogólne i szczegółowe zasady reprezentacji na mapie. Omówione będą wady i zalety wykorzystanych algorytmów.

\section{METODOLOGIA}

\section{Wybór i charakterystyka wód powierzchniowych podlegających generalizacji kartograficznej}

Wybrano cztery obiekty z BDOT10k z warstwy woda powierzchniowa: Jezioro Kierskie, staw Antoninek, Jezioro Strzeszyńskie oraz Staw Baczkowski. Wszystkie obiekty znajdują się w granicach Poznania, a ich położenie na podkładzie ortofotomapy pokazano na rycinie 1 . Źródłem ortofotomapy jest krajowy geoportal. Podstawowym kryterium wyboru wód powierzchniowych było ich zróżnicowanie pod kątem złożoności linii brzegowej. Kryterium dodatkowym, ale równie istotnym w kontekście produkcji urzędowych map topograficznych, było kryterium powierzchniowe, ponieważ zbyt małe obiekty tej klasy nie są prezentowane na mapach, zatem generalizacja ich linii brzegowej staje się bezcelowa.

Wśród wybranych zbiorników wodnych największym jest Jezioro Kierskie będące jeziorem ryn-

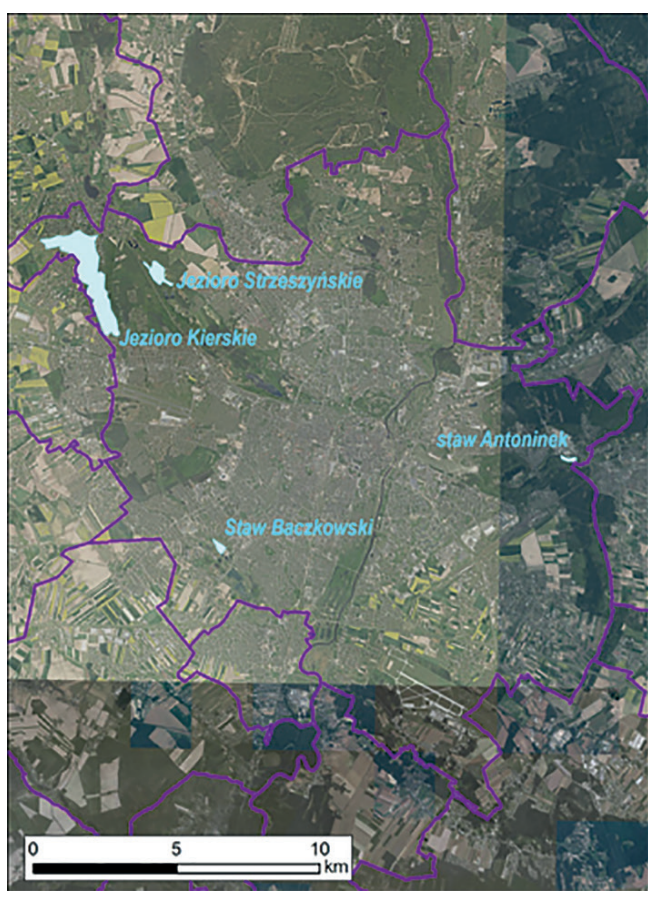

Ryc. 1. - Położenie wybranych jezior na tle ortofotomapy miasta Poznania i okolicznych gmin

Fig. 1. - Location of selected lakes on the background of the orthophoto map of the city of Poznan and surrounding communities 
nowym polodowcowym. Jego zwierciadło wody jest położone na wysokości 72,0 m n.p.m. W BDOT10k powierzchnia zbiornika wynosi 293,74 a w układzie 1992, a w układzie 2000 strefie 6 - 293,99 ha. Drugie co do wielkości Jezioro Strzeszyńskie jest zbiornikiem przepływowym powstałym w wyni$\mathrm{ku}$ zalania zagłębienia terenu przez wody subglacjalne. Powierzchnia jeziora według BDOT10k w układzie 1992 wynosi 36,14 ha, a w układzie 2000 strefa 6 - 36,17 ha. Kolejnym zbiornikiem wodnym jest staw Antoninek, który jest zbiornikiem zaporowym założonym w 1989 r. (Dondajewska 2010). Jego powierzchnia w BDOT10k w układzie 1992 wynosi 7,39 ha i w układzie 2000 strefa $6-7,40$ ha. Ostatnim wybranym zbiornikiem wodnym jest bezodpływowy Staw Baczkowski, który powstał w miejscu wyrobiska po odkrywkowej eksploatacji gliny (Gołdyn i in. 1996, s. 49). Powierzchnia stawu według BDOT10k wynosi 10,64 ha zarówno w układzie 1992, jak i 2000 strefa 6 .

\section{Wybór algorytmów generalizacji w programie ArcMap}

Do uproszczenia geometrii obiektów o charakterze powierzchniowym wykorzystano algorytmy generalizacji, które znajdują się w pakiecie programu ESRI ArcMap 10.5.1. Wykorzystanie tego oprogramowania do generalizacji było już wcześniej przedmiotem zainteresowania niektórych badaczy (Szombara, Kozioł 2010; Karsznia, Leszczuk 2017). W niniejszym badaniu testowano trzy algorytmy upraszczania poligonowej geometrii: point remove, bend simplify oraz weighted area.

Pierwszy algorytm point remove jest klasycznym algorytmem DouglasaPeuckera (Douglas, Peucker 1973). Jego cechą jest to, że najszybciej przetwarza wybrany obiekt. Opiera się na eliminacji punktów na linii podstawowej z wykorzystaniem strefy tolerancji (Medyńska-Gulij 2015, s. 107). Zgeneralizowany obiekt charakteryzuje się bardziej kanciastym kształtem i większą strefą tolerancji.

Drugi algorytm - algorytm Wanga-Müllera (1998) polega na identyfikacji i usunięciu relatywnie nieistotnych załamań. Cechuje go większa wierność geometrii względem kształtu wyjściowego, jednak proces generalizacji zajmuje więcej czasu. W ArcMap jest on zaimplementowany jako bend simplify.

Algorytm weighted area polega na triangulacji opartej na poszczególnych punktach załamania. Trójkąty podlegają wagowaniu na podstawie parametrów płaskości, skośności i wypukłości. Na podstawie wag określa się, czy dany werteks ma zostać usunięty czy nie z zachowaniem jak najwierniejszego kształtu względem geometrii pierwotnej. Jest to algorytm Zhou-Jonesa (2005). 


\section{Generalizacja kartograficzna wybranych jezior oparta na parametrach tolerancji}

Każde jezioro zostało zgeneralizowane przy użyciu wymienionych algorytmów z parametrem tolerancji od $5 \mathrm{~m}$ do $50 \mathrm{~m}$. Wszystkie operacje przeprowadzono w programie ESRI ArcMap 10.5.1. Prezentacja efektów generalizacji kartograficznej przedstawiona jest na rycinach 2-4.
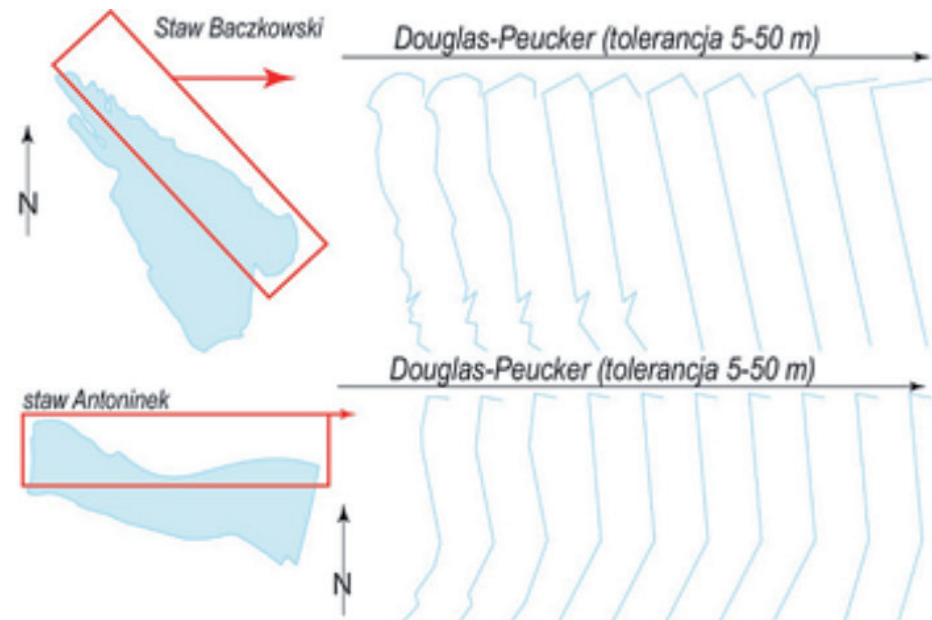

Jezioro Strzeszyniskie

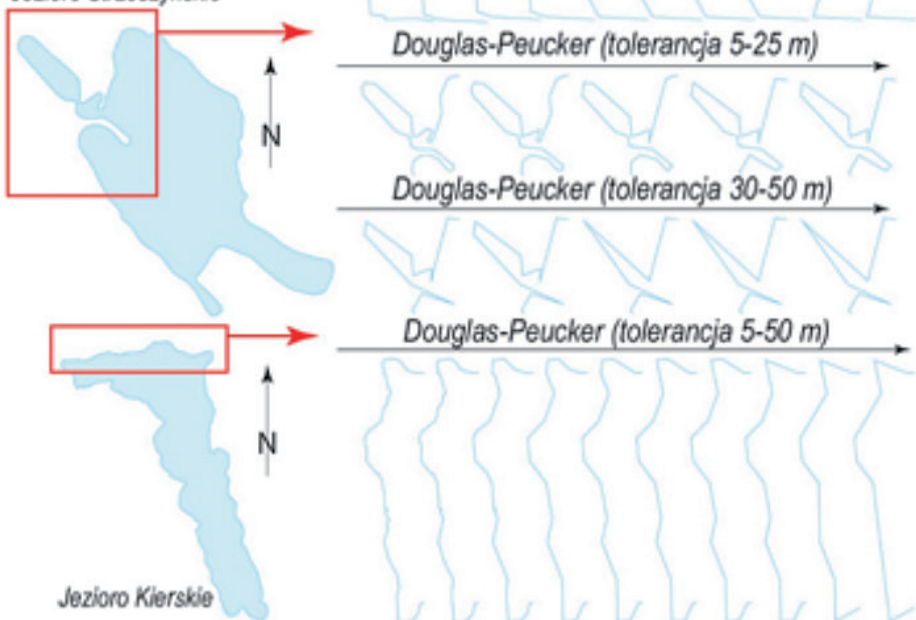

Ryc. 2. - Efekt generalizacji wybranych fragmentów linii brzegowej jezior algorytmem Douglasa-Peuckera o parametrze tolerancji od 5 do $50 \mathrm{~m}$

Fig. 2. - The effect of the generalization of selected fragments of a lake's shoreline using the Douglas-Peucker algorithm with a tolerance

$$
\text { of } 5 \text { to } 50 \mathrm{~m}
$$




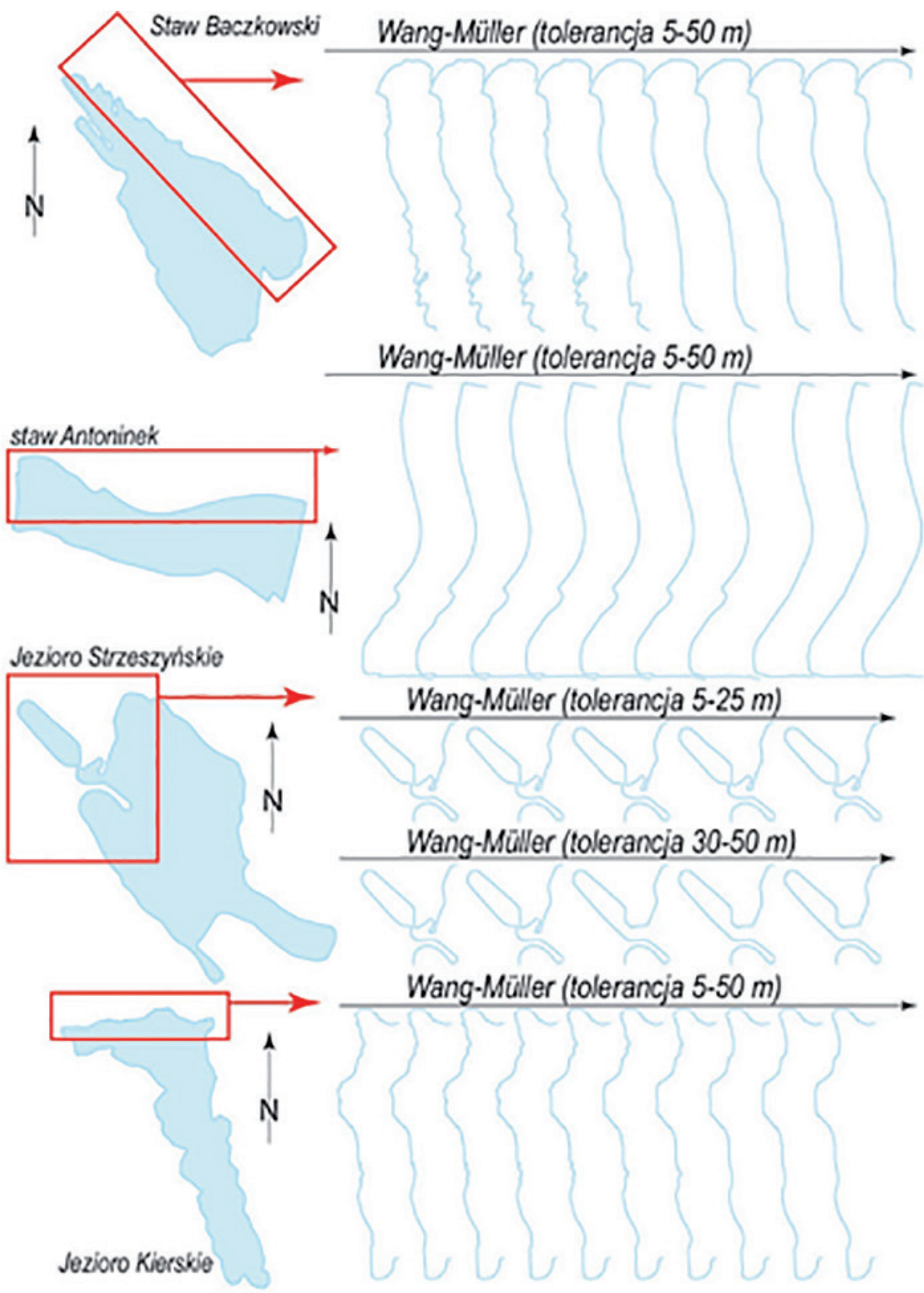

Ryc. 3. - Efekt generalizacji wybranych fragmentów linii brzegowej jezior algorytmem WangaMüllera o parametrze tolerancji od 5 do $50 \mathrm{~m}$

Fig. 3. - The effect of generalization of selected fragments of a lake's shoreline using the WangMüller algorithm with a tolerance of 5 to $50 \mathrm{~m}$ 


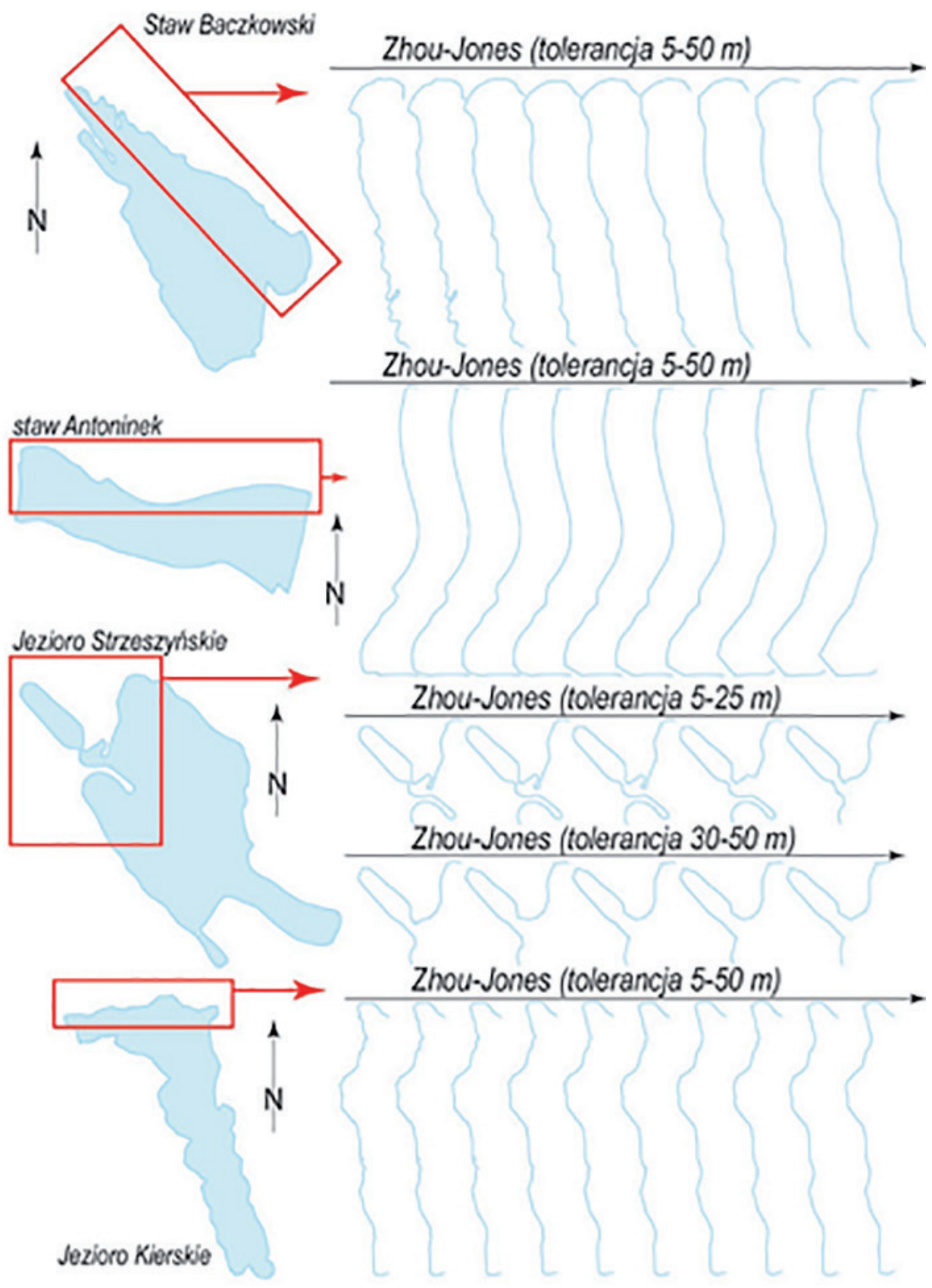

Ryc. 4. - Efekt generalizacji wybranych fragmentów linii brzegowej jezior algorytmem Zhou-Jonesa o parametrze tolerancji od 5 do $50 \mathrm{~m}$

Fig. 4. - The effect of generalization of selected fragments of a lake's shoreline using the Zhou-Jones algorithm with a tolerance of 5 to $50 \mathrm{~m}$ 


\section{WYNIKI BADAŃ}

Pomimo że parametry tolerancji $\mathrm{w}$ algorytmach generalizacji kartograficznej były jednakowe, to zastosowanie różnych sposobów upraszczania geometrii linii brzegowej przyniosło odmienne efekty. Jednym z powodów wykonywania generalizacji jest zmniejszenie skali, w jakiej dany obiekt jest wyświetlany. Dlatego wyniki przedstawiono w różnych skalach. Jedynie Jezioro Kierskie nie zostało przedstawione w całości, ponieważ jest zbyt duże i zaprezentowano jedynie fragmenty jego linii brzegowej. Na rycinie 5 pokazano

\begin{tabular}{|c|c|c|}
\hline $1: 25000$ & $1: 50000$ & $1: 100000$ \\
\hline $\begin{array}{c}\text { Jezioro Kiershie } \\
\text { (poludiniowy fragment) }\end{array}$ & $\begin{array}{c}\text { Jezioro Kierskie } \\
\text { (potudniowy fragment) }\end{array}$ & Jezioro Kierskie \\
\hline $\begin{array}{c}\text { Douglas-Peucker } \\
\text { tolerancja } 5 \mathrm{~m}\end{array}$ & $\begin{array}{c}\text { Douglas-Peucker } \\
\text { tolerancja } 5 \mathrm{~m}\end{array}$ & $\begin{array}{l}\text { Zhouvones } \\
\text { tolerancja } 45 \mathrm{~m}\end{array}$ \\
\hline Jezoro Strzeszyṅskje & Jezioro Stzeszyniskie & Jezioro Strzeszyniskie \\
\hline $\begin{array}{c}\text { Douglas-Peucker } \\
\text { tolerancja } 5 \mathrm{~m}\end{array}$ & $\begin{array}{l}\text { Zhou-Jones } \\
\text { tolerancja } 25 \mathrm{~m}\end{array}$ & $\begin{array}{l}\text { Zhouvones } \\
\text { tolerancja } 40 \mathrm{~m}\end{array}$ \\
\hline staw Antoninek & staw Antoninek & staw Anfoninek \\
\hline $\begin{array}{l}\text { Zhou-Jones } \\
\text { tolerancja } 10 \mathrm{~m}\end{array}$ & $\begin{array}{l}\text { Zhou-vones } \\
\text { tolerancja } 15 \mathrm{~m}\end{array}$ & $\begin{array}{l}\text { Zhou-Jones } \\
\text { tolerancja } 35 \mathrm{~m}\end{array}$ \\
\hline Staw Baczkowski & Staw Baczkowskj & Staw Baczkowskj \\
\hline $\begin{array}{l}\text { Zhou-Jones } \\
\text { tolerancja } 15 \mathrm{~m}\end{array}$ & $\begin{array}{l}\text { Zhouvlones } \\
\text { tolerancja } 20 \mathrm{~m}\end{array}$ & $\begin{array}{l}\text { Zhouvones } \\
\text { tolerancja } 30 \mathrm{~m}\end{array}$ \\
\hline
\end{tabular}

Ryc. 5. - Wybrane jeziora w skalach 1:25 $000-1: 100000$ zgeneralizowane według najbardziej optymalnych parametrów tolerancji

Fig. 5. - Selected lakes at a scale of 1:25 000-1: 100,000, generated according to the optimal tolerance parameters 
uproszczone kształty jezior z optymalnym parametrem generalizacji oraz najbardziej odpowiednim algorytmem do przetwarzania geometrii.

Najbardziej przydatnym algorytmem do generalizacji wybranych jezior okazał się algorytm Zhou-Jonesa. Zachował on wierność kształtu przy jednoczesnej eliminacji werteksów leżących bardzo blisko siebie. Przydatny okazał się również algorytm Douglasa-Peuckera, ale jedynie w większych skalach topograficznych. Zbyt duży parametr tolerancji powodował, że kształty jezior stawały się zbyt kanciaste. Natomiast algorytm Wanga-Müllera okazał się nieprzydatny, ponieważ zachowywał zbyt dużo szczegółów, które powodowały, że linia brzegowa wyglądała na postrzępioną.

W skali $1: 25000$ algorytm generalizacji Douglasa-Peuckera o tolerancji 5 $\mathrm{m}$ był najbardziej optymalny w przypadku uproszczenia linii brzegowej Jeziora Kierskiego oraz Jeziora Strzeszyńskiego. Jezioro Kierskie ze względu na swój stosunkowo prosty (niewielką krętość i bardzo małą liczbę zatoczek) kształt linii brzegowej nie wymagało większego uproszczenia. Uproszczenie linii brzegowej Jeziora Strzeszyńskiego innymi algorytmami powodowało, że jego północno-zachodnia część była nieczytelna w skali $1: 25000$. Zastosowanie większej tolerancji skutkowało poprawą czytelności, ale zbyt mocno zniekształcało linię brzegową w pozostałych częściach.

\section{PODSUMOWANIE}

Algorytmem generalizacji, używając którego, otrzymuje się najlepsze wyniki w przypadku upraszczania linii brzegowej w skalach 1:50 000 oraz 1: 100 000, jest algorytm Zhou-Jonesa. Oddaje on najwierniej kształt jezior i jednocześnie jego aplikacja do narzędzi internetowej generalizacji plików Shapefile lub GeoJSON jest stosunkowo prosta (Harrower, Bloch 2006). W większych skalach map topograficznych, takich jak $1: 10000$ lub $1: 25$ 000, można stosować algorytm Douglasa-Peuckera z zastrzeżeniem, że użyty parametr tolerancji powinien być niski. Jest to spowodowane tym, że większa generalizacja kształtu obiektu będzie powodować jego znaczne zniekształcenie i jeśli dane jezioro nie ma charakterystycznego kształtu, który może być rozpoznany nawet po jego dużej deformacji, nie jest zalecane jego użycie (Kozioł 2013).

Brak szczegółowych specyfikacji dotyczących generalizacji kartograficznej obiektów BDOT10k daje szerokie pole na wykorzystanie zróżnicowanych algorytmów. Oprogramowanie geoinformacyjne oferuje wiele różnych sposobów upraszczania linii brzegowej, ale tylko niektóre z nich mogą być z powodzeniem użyte do opracowania standardowych produktów kartograficznych. Użycie zbyt wysokich lub zbyt niskich wartości tolerancji lub niedostosowanie tego parametru do skali wyjściowej mapy będzie skutkowało nieczytelnym kształtem jeziora, co przekłada się na estetyczne wrażenia odbioru mapy, pomimo tego, 
że ogólne i szczegółowe wytyczne generalizacji zostały zachowane (Moere, Purchase 2011). Wykorzystanie algorytmów generalizacji kartograficznej może przyczynić się do procesu automatyzacji generalizacji, która jest realizacją Dyrektywy INSPIRE (Sielicka, Karsznia 2018).

Różnorodność wód powierzchniowych i ich kształtów nie pozwala jednoznacznie określić jednego algorytmu generalizacji kartograficznej, który mógłby być używany do upraszczania linii brzegowej. Dlatego konieczne jest dalsze testowanie różnych algorytmów z uwzględnieniem procesu automatyzacji lub uczenia maszynowego.

\section{LITERATURA}

Dondajewska R., 2010: The variability of phosphorus fractions in sediments of a shallow, restored Antoninek Reservoir, Limnol. Rev., 10, 2, 59-65.

Douglas D., Peucker T., 1973: Algorithms for the reduction of the number of points required to represent a digitized line or its caricature, The Canadian Cartographer, 10, 2, 112-122.

Gołdyn R., Jankowska B., Kowalczak P., Pułyk M., Tybiszewska E., Wiśniewski J., 1996: Wody powierzchniowe Poznania, [w:] Środowisko naturalne miasta Poznania, cz. 1. Urząd Miejski w Poznaniu, Poznań.

Harrower M., Bloch M., 2006: MapShaper.org: a map generalization Web service, IEEE Computer Graphics and Applications, 26, 4, 22-27.

Karsznia I., Leszczuk M., 2017: Kontekstowa generalizacja konturów zabudowy z wykorzystaniem narzędzi morfologii matematycznej, Roczn. Geomatyki, 15, 2, 77, 187-200.

Kozioł K., 2013: Algorytm upraszczania linii z wykorzystaniem interpolacji, Roczn. Geomatyki, $11,60,3,45-59$.

Medyńska-Gulij B., 2015: Kartografia. Zasady i zastosowanie geowizualizacji, Wyd. Nauk. PWN, Warszawa.

Moere A.V., Purchase H., 2011: On the role of design in information visualization, Inform. Visualization, 10, 4, 356-371.

Olszewski R., 2013: Podstawy prawne budowy baz danych BDOT10k i BDOO, [w:] Rola bazy danych obiektów topograficznych $w$ tworzeniu infrastruktury informacji przestrzennej $w$ Polsce, GUGiK, Warszawa, 58-59.

Sielicka K., Karsznia I., 2018: Automatyzacja procesu generalizacji danych przestrzennych jako realizacja zapisów dyrektywy INSPIRE, Roczn. Geomatyki, 16, 2, 81, 141-152.

Szombara S., Kozioł K., 2010: Automatyczne wyznaczanie punktów osnowy kartograficznej do upraszczania linii brzegowej w procesie generalizacji z wykorzystaniem aplikacji ModelBuilder programu ESRI ArcMap, Geomatyka i Inż., 2, 51-62.

Wang Z., Müller J.-C., 1998: Line Generalization Based on Analysis of Shape Characteristics, Cartography and Geograph. Inform. Syst., 25, 1, 3-15.

Zhou S., Jones C., 2005: Shape-Aware Line Generalization with Weighted Effective Area, [w:] P. Fisher (ed.), Developments in Spatial Handling, 11th International Symposium on Spatial Handling, Springer, Berlin Heidelberg New York, 369-380. 